\title{
Dynamic Simulation of Urban Sustainable Development Based on SD Model
}

\author{
GUAN DongJie ${ }^{1, \text { a }}$ CHEN Ting ${ }^{1}$ ZHOU LiLei $^{1}$ and ZHOU Jian $^{2}$ \\ ${ }^{1}$ College of Architecture and Urban Planning, Chongqing Jiaotong University, No.66 Xuefu Rd., \\ Nan'an Dist., Chongqing 400074, China \\ ${ }^{2}$ College of Public Health, Jiamusi University, No.148 Xuefu Rd., Jiamusi 154007, China \\ aguandongjie_2000@163.com
}

\begin{abstract}
Keywords: Sustainable development; System dynamics; Economy-resource-environment system; Chongqing in China

Abstract. The coordinated development of Economy-Resources-Environment (ERE) is a key component of sustainable development. Based on the connotation and framework of sustainable development of urban ERE, this paper employs the theory and methodology of System Dynamics (SD) to elucidate the economic growth constrained from urban resource depletion and environmental degradation. Herein, resource, environment, and technology subsystems are combined with economy subsystem into a Cobb-Douglas production. Meanwhile, five scenarios, named current, resources, environment, technology and economy, are designed to compare the simulation results, so that the effects of different scenarios on the urban ERE can be emphasized. The results demonstrate that the current development of Chongqing is unsustainable, and the optimization of any one subsystem cannot realize the sustainable development. It turns out that the transformation of the economic development mode is the only way to sustainable development in Chongqing, and feasible transformation ways of the economic development mode have been put forward.
\end{abstract}

\section{Introduction}

In recent years, environmental issues associated with rapid economic development have attracted critical concerns of the national and local governments ${ }^{[1]}$. Urban economic growth is a complicated process that is mainly determined with an interaction between resource depletion and environment pollution in space and time at different scales ${ }^{[2]}$. Aiming at promoting economic development, as well as public awareness of environmental issues, local authorities have been undertaking the enhanced pressure for effective response to these concerns. In general, a reliable path for dealing with this dilemma is to frame effective environmental management regulations and policies for a region-specific system. This decision-making process requires well understanding of the significant contributors to regional environmental problems and of the way that the environmental management system will react to particular policies ${ }^{[3]}$. During this process, it's essential to understand the interactions among a number of related social, economic, environmental, managerial, regulatory, and lifestyle factors. These interactions are complicated, not only because they simultaneously involve various system components but because they dynamically change over time. As a municipality in the southwestern China, Chongqing's economic development has been subjected to the constraints from resource and environment. How to solve these developmental bottlenecks and achieve the sustainable development of economy, resources, and environment is one of the most vital issues at present. Herein, we develop a novel SD model as a planning decision-support tool to deal with the dilemma of continuous urban economy growth against limited resource depletion and environment deterioration in Chongqing city of China.

\section{Methodology}

The SD model studies the sustainability of an ERE system according to cybernetics, system theory, and information theory. It can elucidate the interaction and relationship among many influencing 
factors prior to a dynamic simulation test. This test can investigate the changing behaviors and tendencies of the ERE system in alternative scenarios so that the corresponding policies and managements can be verified. The model is written in a Vensim software with a time step of 1 year and a time span of 50 years (2000-2050). The core of the SD model is a Cobb-Douglas production function in a form of $Y=H \cdot L^{a} K^{b} R^{c} M^{d}$. Herein, $Y$ is the production; $H$ is the technology level in production; $L$ is the labor input; $\mathrm{K}$ is the capital input; $\mathrm{R}$ is the flow of renewable resource input; $\mathrm{M}$ is the flow of non-renewable resource input; the sum of $\mathrm{a}, \mathrm{b}, \mathrm{c}$, and $\mathrm{d}$ are constant as 1, indicating the constant returns to scale ${ }^{[4]}$. When it is unconstrained, the Cobb-Douglas function allows the smooth substitution with the diminishing returns among the factors of production. They are separately corresponded to the six sub-systems in the whole ERE system. Besides the six subsystems, there are still two other indispensable sub-systems, population and environment. The total eight sub-systems, as well as interaction and feedback among them, determine the probable scenarios of the ERE system. Fig.1 presents the contents, structures, and stock-flow diagrams of the subsystems. The ERE system includes 79 parameters. Among them, 9 parameters are considered as level variables; 17 parameters are considered as rate variables; 53 parameters are considered as assistant variables. The detailed contents are shown in Table 1.

Table 1 Parameters list of ERE system in Chongqing

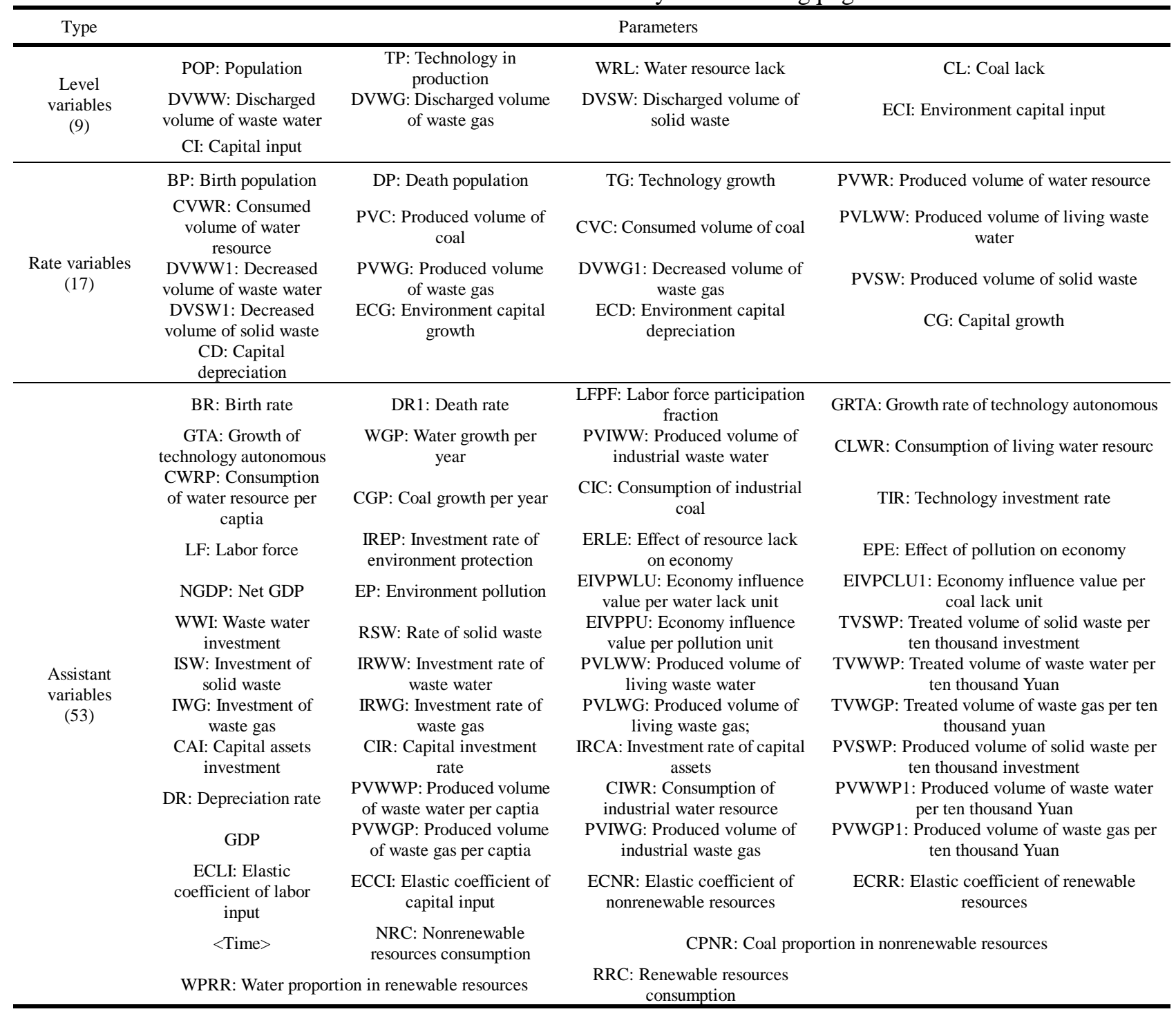




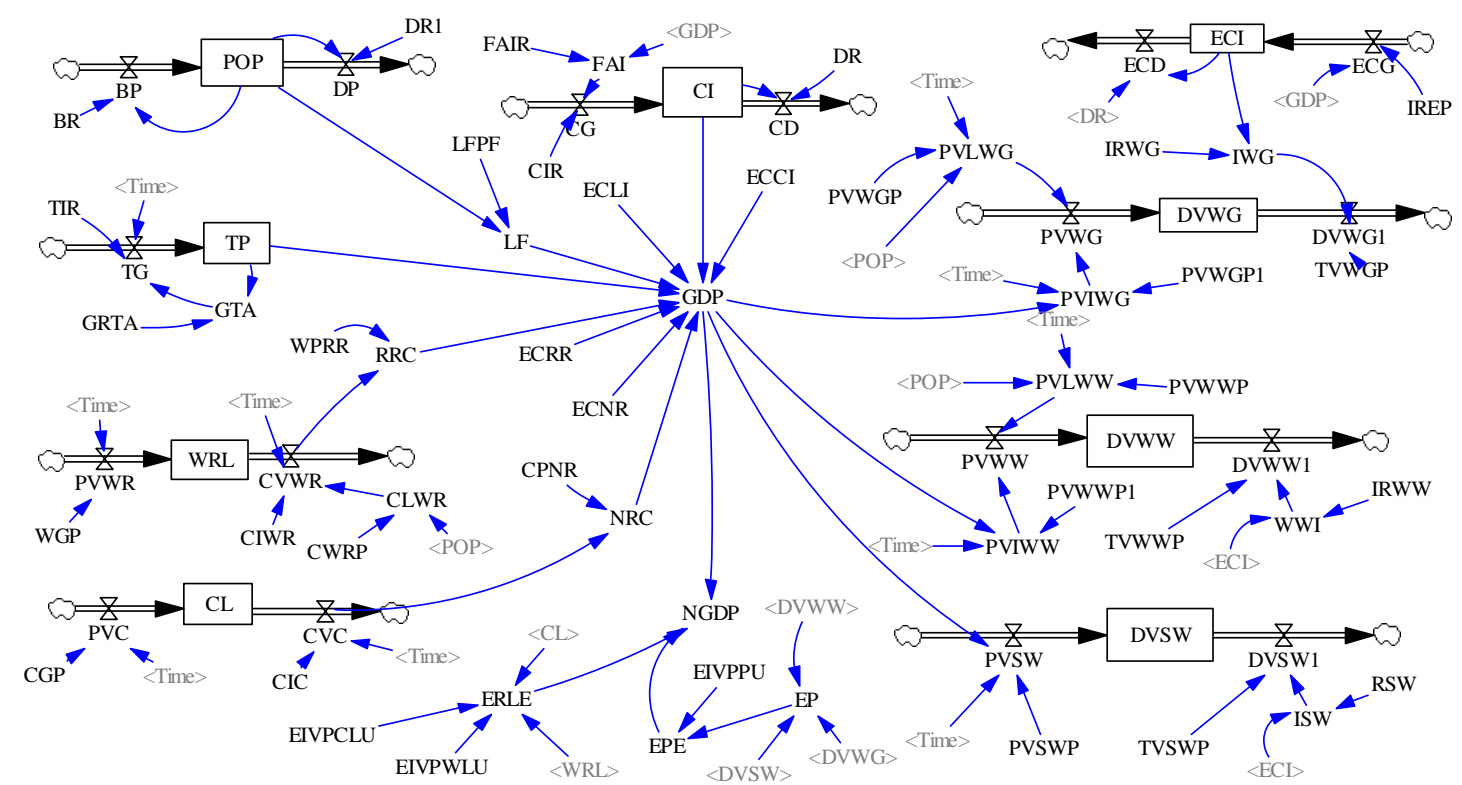

Fig.1 Stock-flow diagram of ERE system in Chongqing

\section{Results and Discussions}

In this study, five typical scenarios are compared in Table 2. At present, Chongqing is improving its economy system through the guidelines of market economy to promote the urban competitive power. Accordingly, current scenario is to sustain the base runs of all subsystems. Second, economy development of Chongqing depends very strongly on natural resource, especially non-renewable resource. So, resource scenario is to reduce the depletion speed of natural resource and to increase the input of labor force and capital. Third, because environment problems become very serious as the evolution of economic growth, environment scenario is to increase the investment of environment protection and to control the discharged volumes of waste gas, waste water, and solid waste. Fourth, technological progress can ensure sustainable economic growth while ignoring the constraint of nonrenewable resources. Thus, technology scenario is to improve the technology level to increase the output. Finally, economy scenario is to adjust the capital assets investment for sustainable development of economy and environment system. Increasing and reducing the investment in the capital assets are designed in the economy scenario.

Table 2 Setting of different scenario parameters

\begin{tabular}{llllll}
\hline \multicolumn{1}{c}{ Parameters } & $\begin{array}{l}\text { Current } \\
\text { scenario }\end{array}$ & $\begin{array}{l}\text { Resource } \\
\text { scenario }\end{array}$ & $\begin{array}{l}\text { Environment } \\
\text { scenario }\end{array}$ & $\begin{array}{l}\text { Technology } \\
\text { scenario }\end{array}$ & $\begin{array}{l}\text { Economy } \\
\text { scenario }\end{array}$ \\
\hline Elastic coefficient of renewable resources & 0.05 & 0.02 & 0.05 & 0.05 & 0.05 \\
Elastic coefficient of nonrenewable resources & 0.2 & 0.1 & 0.2 & 0.2 & 0.2 \\
Elastic coefficient of labor input & 0.32 & 0.35 & 0.32 & 0.32 & 0.32 \\
Elastic coefficient of capital input & 0.43 & 0.53 & 0.43 & 0.43 & 0.43 \\
Investment rate of environment protection & 0.025 & 0.025 & 0.05 & 0.025 & 0.025 \\
Technology investment rate & 0.02 & 0.02 & 0.02 & 0.2 & 0.02 \\
Investment rate of capital assets & 0.366 & 0.366 & 0.366 & 0.366 & $0.6 / 0.2$ \\
\hline
\end{tabular}

We compare the five scenarios of current, resource, environment, technology, and economy. In the viewpoint of economy, the development mode of the assets capital increase gives a fastest GDP increase; the resource mode gives a second fastest GDP increase; the development mode of the assets capital decrease gives a slowest GDP increase. The net GDP has the same decreasing sequence in the modes of increasing capital assets, resource scenario, and reducing capital assets, as seen in Fig.2. In the viewpoint of resource, the resource consumption amount is the smallest in the resource scenario, the economy lag deduced by the resource shortage can be amended by the investments of labor and capital. In the viewpoint of environment, the emission amount of pollution has a direct relationship with the GDP. The pollution amount is the biggest in the scenario of increasing the assets capital, and the 
second biggest in the environment scenario; in the scenario of reducing the assets capital, the amount of environment pollution is the lowest, as seen in Fig.3.

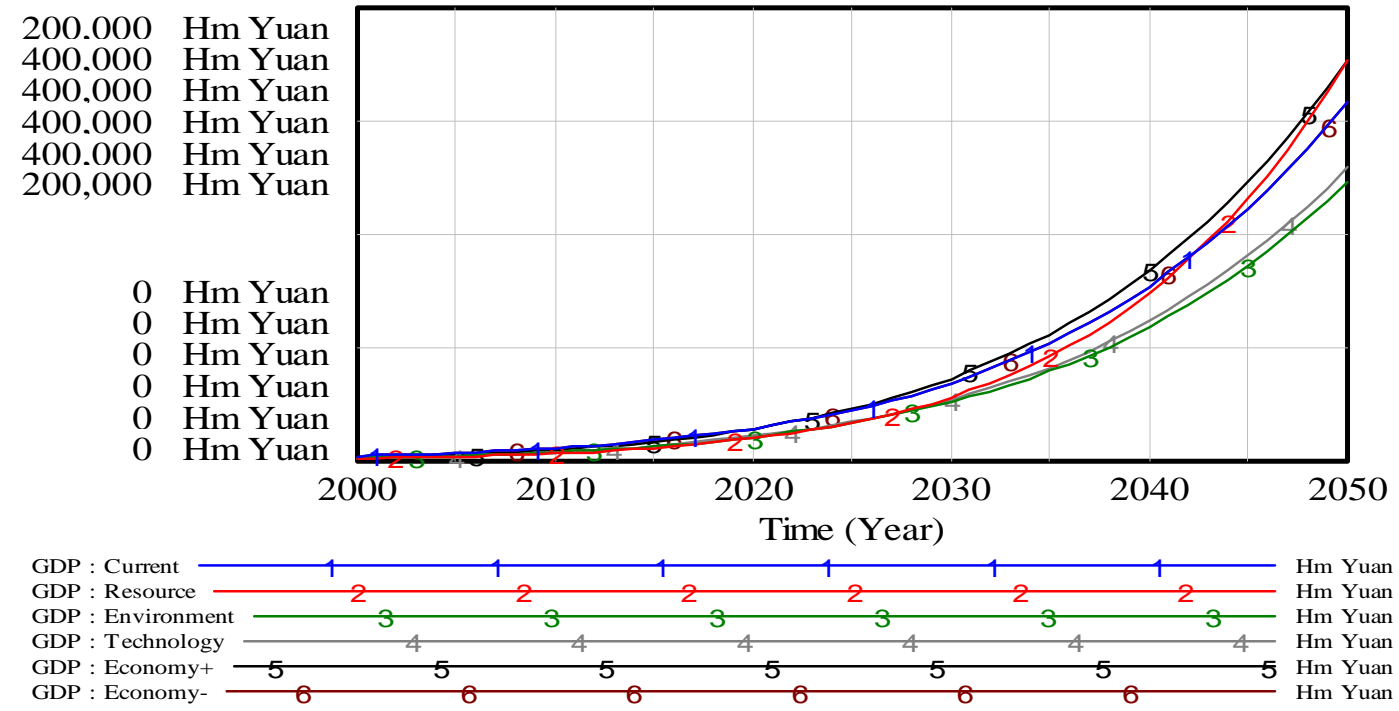

Fig.2 Results of GDP under different scenarios

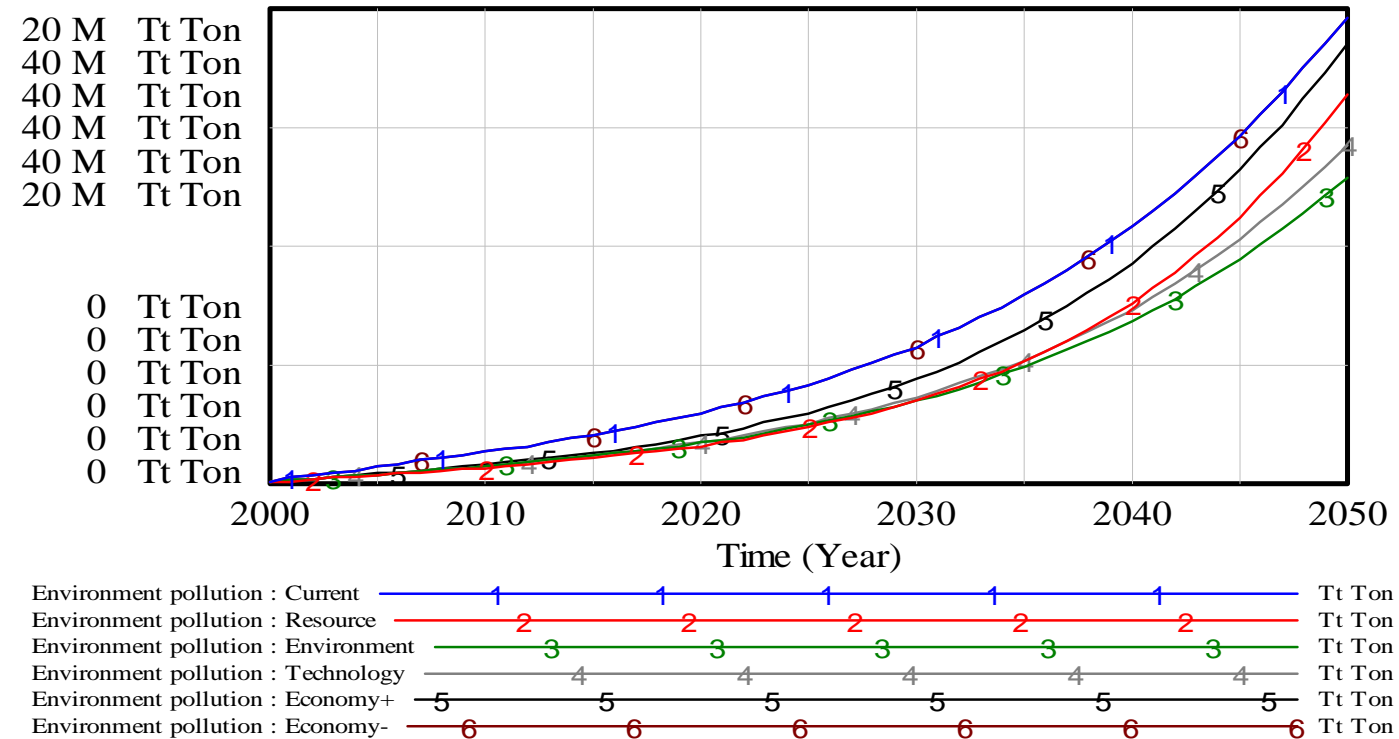

Fig.3 Results of environment pollution under different scenarios

As a consequence, increasing the assets capital investment is most effective for the GDP increase, but deteriorating the environment. Thus, the economy increase is at the expense of environment pollution. In the resource scenario, although resource doesn't suffer from the serious destruction, Chongqing is lack of resource. Hence, economy development will be seriously restricted unless the lack gap of resource is amended in time; the environment deterioration is also severe. In the environment scenario, the GDP profit is not the highest, but environmental deterioration is effectively suppressed. So, the adjustment of the subsystem cannot achieve Chongqing's sustainable development, 
only if the transformation of the economy development mode is the exclusive approach to the Chongqing's sustainable development.

Chongqing locates in three gorges tail area, which makes Chongqing metropolis and three gorges depend on each other. Since social economic driving of metropolis interacts with vulnerable eco-environment in three gorges, ecosystem security in Chongqing metropolis is quite unique and vulnerable. Moreover, it appears a series of severe eco-environmental problems always restricting sustainable development of eco-security in Chongqing metropolis. Therefore, it is meaningful to establish SD model for elucidating the economic growth constrained from urban resource depletion and environmental degradation of Chongqing metropolis and simulate urban sustainable development in a scientific way.

\section{Conclusions}

According to theory and methodology of system dynamics, this study discusses the programming of ERE system, and develops an SD model by which five typical scenarios are proposed for comparative analysis. The main conclusions demonstrate that: (1) Under the current scenario, only the total amount of economic development is expanded; resource will appear a lacking gap. The ignorant of environment and resource will cause the collapsing economy system. (2)Under the resource scenario, the speed of economy growth is reduced with the decreasing dependence degree on natural resource in a short period. However, the resource system will support a longer time development of economy system. (3) Under the environment scenario, the investment of environment protection extends the breakdown time of economy system. Nevertheless, it is inevitable that economy system will collapse due to the depletion of natural resource. (4)Technology scenario will not only increase the GDP amount but also decrease the consumption rate of natural resource, which is favorable for the sustainable development of economy system. However, the scenario cannot improve the environment quality. (5) Under the economy scenario, increasing or reducing the investment in the capital assets has a different influence on the economy development. However, the scenario cannot realize the environment sustainable development.

\section{Acknowledgements}

This work is partially supported by Late Project of National Social Science Foundation in China (No. 16FJY010), National Natural Science Foundation of China (No. 41201546), Basic Science and Advanced Technology Fund of Chongqing Scientific Council in China (No. cstc2017jcyjAX0210).

\section{References}

[1] V. Shandas, J.K. Graybill and C.M. Ryan: Incorporating ecosystem-based management into urban environmental policy: a case study from western Washington. J. Environ. Plann. Manag., Vol.51(2008), p.647-662.

[2] U. Helldén: A coupled human-environment model for desertification simulation and impact studies. Global Planet Change, Vol.64(2008),p.158-168.

[3] H. Guo, L. Liu, G. Huang, G. Fuller, R. Zou and Y Yin: A system dynamics approach for regional environmental planning and management: A study for the Lake Erhai Basin. J. Environ. Manag., Vol.61(2001), p.93-111.

[4] C.W. John, A simulation model to illustrate feedbacks among resource consumption, production, and factors of production in ecological-economic systems. Ecol. Model., Vol.112(1998), p.227-247. 